\title{
Level of Factors impact on the Buyers' Intention in Buying Private Health Insurance with the Case of Vietnam Non-Life Insurance Companies
}

\author{
Nguyen Nhat $\mathrm{Ha}^{1} \quad$ Nguyen Thi Hai Duong ${ }^{2 *} \quad$ Nguyen Thai Son $^{3}$ \\ Bui Quynh Anh ${ }^{4}$ Tran Tien Dung ${ }^{4}$ \\ 1.School of Banking and Finance, National Economics University, 207 Giai Phong Road, Hanoi, Vietnam \\ 2.Faculty of Insurance, National Economics University, 207 Giai Phong Road, Hanoi, Vietnam \\ 3.School of Banking and Finance, National Economics University, 207 Giai Phong Road, Hanoi, Vietnam \\ 4.Faculty of Insurance, National Economics University, 207 Giai Phong Road, Hanoi, Vietnam
}

\begin{abstract}
The study aims to determine the influence of factors affecting the intention to purchase private health insurance at non-life insurance companies in Vietnam. The samples were surveyed from 500 people from many areas but mostly in Hanoi. The study identified and clarified 5 independent factors affecting the intention to buy private health insurance at non-life health insurance companies in Vietnam. The analysis results show 5 variables: "Past experience", "Perception of service quality of insurance companies", "Perceived behavioral control", "Attitude towards risks and private health insurance ", and the variable "Subjective norms on private health insurance" affect people's intention to buy private health insurance. Several policies have been proposed to increase customers' intention to buy private health insurance at non-life insurance companies from the analysis. To raise customer's intention to purchase private health insurance, the research team recommends non-life insurance company to improve service quality, especially after-sales service, the quality and expertise of staff, and the government to complete policies and legal framework on private health insurance. Moreover, the research team also recommend to renovate the quality of organizing the private health insurance regime and form the basis of the entire population pathology record.
\end{abstract}

Keywords: private health insurance, intention to purchase, non-life insurance company.

DOI: $10.7176 / \mathrm{EJBM} / 12-27-06$

Publication date:September $30^{\text {th }} 2020$

\section{Introduction}

Health insurance acts as a mechanism to ensure that people have access to medical care when the amount spent for medical examination and treatment exceeds their ability to pay. However, in Vietnam, state health insurance coverage does not meet all medical expenses. The proportion of people's out-of-pocket medical expenses is high up to $37 \%$ of the total medical examination and treatment cost (Phuong Chi, 2019). The health insurance fund does not guarantee full coverage of healthcare needs and services, and the level of financial coverage is limited.

To overcome the limitations of state health insurance, each country has different measures and financial instruments. However, the development of commercial health insurance is often encouraged by governments to promote motivating resources for medical examination and treatment. In Vietnam, the mobilization of resources in health insurance through the promotion of commercial health insurance is considered a critical orientation of the Vietnamese Government in the coming time (Committee of the Communist Party, 2017). This study determines the influence of factors on commercial health insurance buying behavior, thereby proposing a solution to raise people's intention to purchase private health insurance, and increasing participation in commercial health insurance contributes to lower out-of-pocket health insurance coverage in Vietnam.

\section{Literature Review}

Studies on the factors affecting the intention of purchasing private health insurance were approached in many ways and views but mostly from the classical economy view with micro and macroeconomic factors. Some of them were recently approached from the view of behavioral psychology and showed new features and findings.

Research by Brownie \& Kim (1993) identifies macroeconomic factors in health insurance demand. They point out that national income, inflation, government spending, and demographics are important factors in creating health insurance needs. Next, researchers Beck \& Webb (2003) confirm that inflation and demographics influence health insurance purchases. Lee et al. (2010) also concluded that demographic and economic factors influence household health insurance needs. Similarly, Bhat \& Jain (2006) show that the number of children in families, the age, and awareness of future medical care costs affect insurance purchase. Alternatively, for the number of health insurance purchases, income has shown a significant relationship, namely that those with high incomes buy health insurance more than low income (Yamada et al., 2009). From a microeconomic perspective, Berry (1995) points out that the company's context, the product transformation, and the complexity of insurance are essential factors that create a 
demand for health insurance.

However, the above theoretical research models cannot explain every case, such as the health insurance market in Indonesia. To an economy with a reasonable growth rate and improved domestic education, the demand for health insurance in Indonesia declined, contrary to the evidence presented in the research papers above (Pitriyan \& Siregar, 2013). The findings of Auerbach and Kotlikoff (1991) explain the differences in Indonesia by proving that insurance purchases rarely follow benefits. They have provided evidence that the demand for health insurance is not always about economic and demographic factors. The majority of people with health insurance do not really need insurance.

Scholars have had to assess the psychological factors to discover irregularities in economic activities through behavioral studies. For example, in Indonesia's insurance phenomena, the case study by Rabin \& Thaler (2001) suggests that risk aversion may explain the anomalies in the insurance market where people tend to buy insurance when they should not and vice versa, tend to refuse when they really need to.

Another typical research about private health insurance purchasing intention in India is Thomas's (2013) findings. In this research, he classified 3 main factors: personal, marketing, and social factors. Personal factors included consumer's attitudes and consumer awareness, which are also related to behavioral psychology. Marketing factors were approached 7Ps of marketing, which included People, Processes, and physical evidence like the product, price, place, and promotion. In contrast, the social factors referred to the rising social awareness, increasing risk, and the rising cost of healthcare.

In Vietnam, there are not many studies related to private health insurance. The research team is based on similarity and references research on health insurance and voluntary health insurance in Vietnam. The domestic studies mainly approach from the classical economic direction. Le et al. (2017) found that demographic factors and health status include gender, education level, propaganda, and the number of medical examinations and treatments that affect people's decision to buy voluntary health insurance.

Considering the elements of microeconomics, Nguyen et al. (2018) have identified 6 groups of factors that strongly influence households' participation in voluntary health insurance. They include administrative procedures, level of knowledge about health insurance, income, and social insurance, medical examination and treatment facilities, quality of medical examination and treatment services, and voluntary medical insurance premiums.

After consulting the previous scientific studies, the team decided to combine and research both aspects but mainly from behavioral psychology.

\section{Methodology}

The theoretical basis to be exploited is the theory of health insurance, the theory of Planned Behavior, the intention to buy health insurance, and the factors affecting the intention to buy health insurance. First of all, the health insurance theory provided relevant knowledge about health insurance such as definition, classification, position in the insurance market, operating principles, value, and role to individuals, families, and society. Next, our group refers to the theories of behavioral psychology such as the Theory of Reasoned Action (TRA), Theory of Planned Behavior (TPB), the MODE model, etc. in order to understand the mechanism of planned behavior and at the same time, learn more about these theories' relevance to the insurance industry in general and health insurance in particular. As a result, our team has identified factors that will undoubtedly influence consumers' intention to buy health insurance and built a model. 


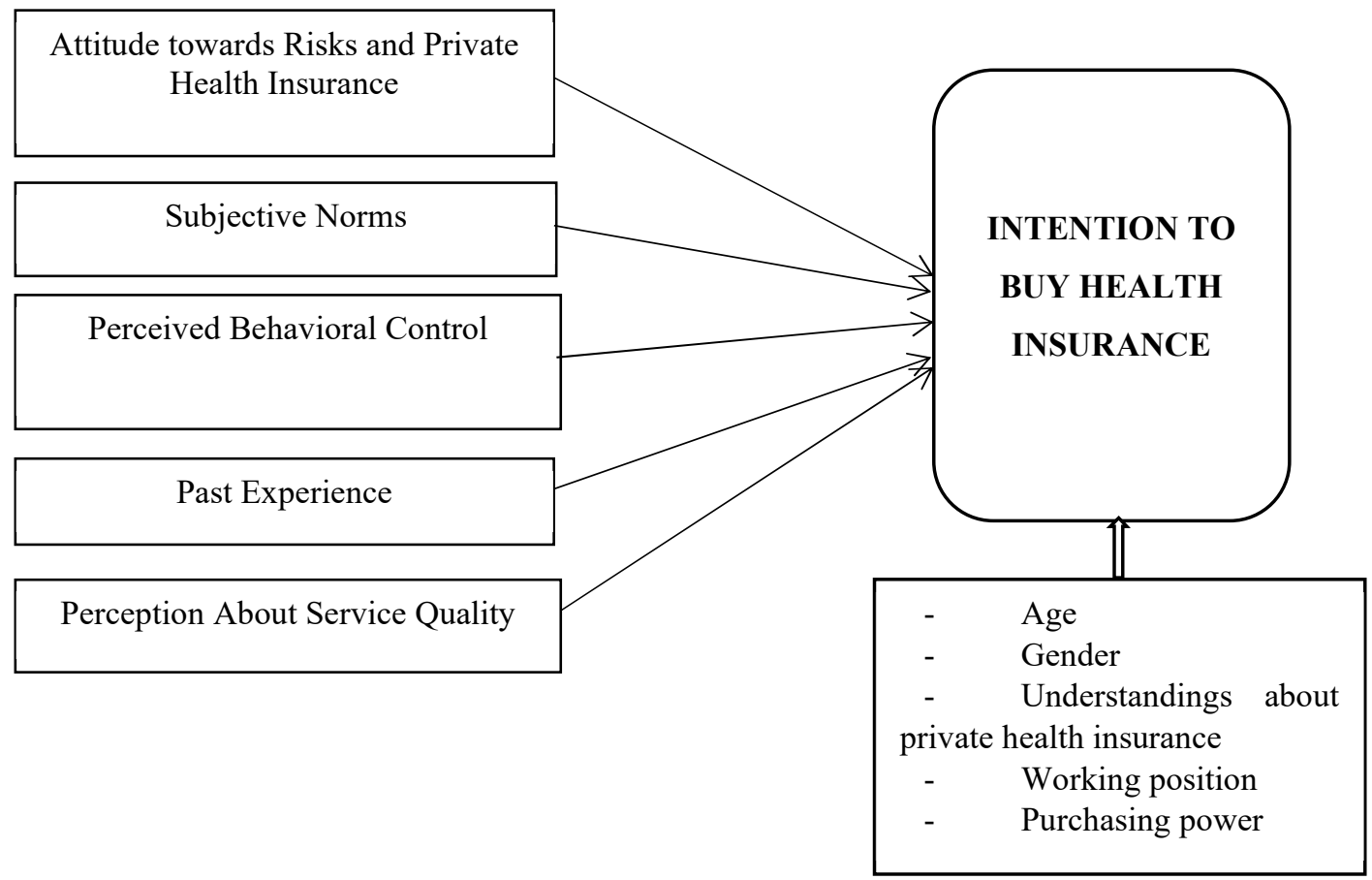

Figure 1: Research Model

The team found 5 factors that influence the intention to buy health insurance at non-life insurance companies in Vietnam included: Attitude towards Risk and private Health Insurance, Subjective Norms, Perceived Behavioral Control, Past Experience, Perception about Service Quality.

The factor "Attitude towards risk and private health insurance" refers to customers' feeling that they are afraid of risk. They realize that private health insurance can reduce risk and provide a sense of security. They also worry about catastrophic financial losses when there are serious risks, need financial security in case of health risks, and fear of medical expenses.

Subject Norms are defined as the perception of an individual and its influencers that behavior should or should not be performed. That is, a person will want to buy private health insurance if they and the people around them like family, friends, and co-workers, feel they should. It includes that influencers say private health insurance is helpful. Almost every one voters know using it, employers buy it for voters, and many sources remind them that health care insurance is necessary.

Perceived behavioral control shows how well an individual feels about the ability to perform a behavior related to the perception of how easy or difficult it is to perform a behavior. In this study, the behavioral control factor refers to whether the respondents have considered buying health insurance or not, whether the respondent's financial ability allows insurance purchase, insurance, or the preparation to buy the insurance and even seek information before purchasing.

The factor of experience includes many service-related criteria such as excellent and convenient service, easy to buy insurance, convenient procedure, and easy to use.

When assessing the factor "perceptions about the service quality of insurance companies", the research team access on the following criteria: Diversified insurance company's products, favorable product distribution channels, staff enthusiastically explained, simple insurance purchase procedure, knowledgeable staff, reasonable insurance premium, the procedure for receiving insurance's advantages.

\subsection{Questionnaire}

The questionnaire was designed based on a Likert scale from "1 - Totally Disagree" to "5 - Totally agree". Sample: 523 people, including employees, managers, students, etc. This research has 5 variables to analyze the influence affecting the intention to buy health insurance at non-life insurance companies in Vietnam, so our team decided to select a sample size of over 500. The final valid votes are 500 votes. This data will be used for further analysis.

\subsection{In-depth interview}

To ensure the research project's accuracy, our group conducted an in-depth interview with 5 experts specialized in health insurance in Vietnam. The questionnaires were adjusted to be more specific and appropriate after. 


\section{Analytical Results}

Cronbach's alpha is used to measure the reliability of the variables. The results are as follow:

Cronbach's Alpha statistics for independent variable scales including "Perception About Service Quality", "Past experience", "Attitude towards Risk and Private Health Insurance ", "Perceived Behavioral Control" and "Subjective Norms" are respectively $0.926,0.888,0.879,0.789$ and 0.766 which is relatively high. EFA factor analysis required greater than 0.5 , so all of the variables can be retained. After reliability and value checking, all scales have been re-tested to ensure the next analyzes requirements.

Table 1: Correlation analysis

\begin{tabular}{|c|c|c|c|c|c|c|}
\hline \multicolumn{7}{|c|}{ Correlations } \\
\hline & & Intention & X1 & $\mathbf{X 2}$ & X3 & $\mathrm{X4}$ \\
\hline \multirow{5}{*}{ Pearson Correlation } & Intention & 1.000 & .595 & .580 & .444 & .526 \\
\hline & X1 & .595 & 1.000 & .545 & .510 & .563 \\
\hline & $\mathrm{X} 2$ & .580 & .545 & 1.000 & .452 & .557 \\
\hline & $\mathrm{X} 3$ & .444 & .510 & .452 & 1.000 & .473 \\
\hline & $\mathrm{X} 4$ & .526 & .563 & .557 & .473 & 1.000 \\
\hline
\end{tabular}

Source: Data analysis results of the research team

Correlation analysis has been conducted to verify the relationship among quantitative variables through Pearson's correlation coefficient (r). The correlation coefficients in the table below show the relationship among variables is relatively reasonable in both direction and strength. Specifically, all correlation coefficient values are more significant than 0 , less than 0.8 , and have both positive and negative signs which reflect either a positive or negative relationship. The relationship between dependent and independent variables has meaning without abnormal signs. Also, the correlation coefficients' strength ensures that there is no multi-collinearity phenomenon occurs when using a linear regression model. Therefore, other statistics could be used to verify the relationship among variables.

Table 2: Descriptive statistics

\begin{tabular}{|c|c|c|c|}
\hline \multicolumn{3}{|c|}{ Descriptive Statistics } & $\mathrm{N}$ \\
\hline & Mean & Std. Deviation & 500 \\
\hline Intention & 3.5313 & .79670 & 500 \\
\hline X1 & 3.4282 & .64112 & 500 \\
\hline X2 & 3.6740 & .70058 & 500 \\
\hline X3 & 4.0625 & .70032 & 500 \\
\hline
\end{tabular}

Source: Data analysis results of the research team

Table 2 shows the result of the descriptive statistics. All variables have average (Mean) varies from 3 to 4 , $\mathrm{X} 3$ has the highest mean (4.0625) while X4 has the lowest mean (3.3653). The lowest standard deviation is X1 at 0.64112 , and the highest one is the intention at 0.79670 . From these results, it can be said that questionnaires must have received many "agree" answers.

Table 3: Model Summary

\begin{tabular}{|c|c|c|c|c|c|c|c|c|c|c|}
\hline \multicolumn{11}{|c|}{ Model Summary } \\
\hline \multirow[b]{2}{*}{ Model } & \multirow[b]{2}{*}{$\mathrm{R}$} & \multirow[b]{2}{*}{ R Square } & \multirow[b]{2}{*}{$\begin{array}{c}\text { Adjusted R } \\
\text { Square }\end{array}$} & \multirow[b]{2}{*}{$\begin{array}{l}\text { Std. Error of } \\
\text { the Estimate }\end{array}$} & \multicolumn{5}{|c|}{ Change Statistics } & \multirow[b]{2}{*}{$\begin{array}{l}\text { Durbin- } \\
\text { Watson }\end{array}$} \\
\hline & & & & & $\begin{array}{c}\text { R Square } \\
\text { Change }\end{array}$ & F Change & df1 & df2 & $\begin{array}{l}\text { Sig. F } \\
\text { Change }\end{array}$ & \\
\hline 1 & $.685^{\mathrm{a}}$ & .469 & .465 & .58293 & .469 & 109.269 & 4 & 495 & .000 & 1.992 \\
\hline \multicolumn{11}{|c|}{ a. Predictors: (Constant), X4, X3, X2, X1 } \\
\hline
\end{tabular}

Source: Data analysis results of the research team

According to the estimated model result, R Square $=0.469$, which means independent variables in the model could explain $46.9 \%$ of the overall level of the intention to buy private health insurance at non-life insurance companies in Vietnam. This result can be considered acceptable in a model. 
Table 4 Coefficient of the regression model of determinants of the intention to buy health insurance at non-life insurance companies in Vietnam

\begin{tabular}{|c|c|c|c|c|c|c|c|c|}
\hline \multicolumn{9}{|c|}{ Coefficients } \\
\hline \multirow{2}{*}{\multicolumn{2}{|c|}{ Model }} & ardized & fficients & $\begin{array}{c}\text { Standardized } \\
\text { Coefficients }\end{array}$ & $t$ & Sig & \multicolumn{2}{|c|}{ Collinearity Statistics } \\
\hline & & B & Std. Error & Beta & & & Tolerance & VIF \\
\hline \multirow{5}{*}{1} & (C) & .061 & .178 & & .341 & .733 & & \\
\hline & $\mathrm{X} 1$ & .386 & .054 & .311 & 7.098 & .000 & .561 & 1.784 \\
\hline & $\mathrm{X} 2$ & .329 & .048 & .289 & 6.815 & .000 & .595 & 1.681 \\
\hline & $\mathrm{X} 3$ & .095 & .045 & .083 & 2.079 & .038 & .671 & 1.490 \\
\hline & $\mathrm{X} 4$ & .165 & .047 & .151 & 3.476 & .001 & .572 & 1.749 \\
\hline & & & & a. Dependent & iable: & ention & & \\
\hline
\end{tabular}

Source: Data analysis results of the research team

Table 4 shows that the Sig ratio of a slope coefficient, which is higher than 0.05 , will not be statistically significant at a 5\% significance level. From these results, that the Sig coefficient of independent variables, including $\mathrm{X} 1, \mathrm{X} 2, \mathrm{X} 4$ is less than 0.01 , it can be said that independent variables are statistically significant at $1 \%$ in significance level. The Sig coefficient of the X3 variable is less than 0.1 , which means this variable is statistically significant at $10 \%$ in significance level. Diminutive order of the impact level of 5 determinants is (1) X1 (standardized $\beta$ coefficient is .311), (2) X2 (standardized $\beta$ coefficient is .289), (3) X4 (standardized $\beta$ coefficient is .151), (4) X3 (standardized $\beta$ coefficient is .083)

According to the regression model, a standardized $\beta$ coefficient, which is greater than 0 , shows a positive relationship among independent variables and the intention to buy health insurance at non-life insurance companies in Vietnam. Therefore, the intention to buy health insurance at non-life insurance companies in Vietnam is mainly assessed from the highest to the lowest: X1 - Perception About Service Quality+Past experience, X2 - Attitude towards Risks and private health Insurance, X4 - Subjective Norms, and X3 - Perceived Behavioral Control.

\section{Recommendation}

Health insurance plays a vital role in ensuring and enhancing social security and improving the community's living standards. The result of the analysis showed that all of these factors influence the intention of purchasing health insurance, and are arranged as above with a gradual decrease in the impact on consumers' intention of purchasing.

\subsection{Past Experience}

Insurance companies are too focused on selling, not investing in after-sale services, and general customer care. Therefore, the research team proposes companies to build a customer care team, take care of after-sale issues, and settle compensation quickly to ensure benefits and increase customer satisfaction. More specifically, for customers to feel comfortable using the insurance policy, instructions for the claimant's claim should be clear, detailed, and easy to access. Procedures should be streamlined based on standard procedures to avoid wasting time on customers and the company. Simultaneously, to speed up customer claims processes, non-life insurers can build, complete, and optimize software, applications, and databases for customer's goods and insurance personnel.

\subsection{Perception About Service Quality}

Firstly, non-life insurance companies need to diversify their products to suit different customer segments and different needs.

Secondly, the research team recommends diversifying distribution channels through a new insurance distribution model - Bancassurance. Simultaneously, combining with promoting traditional channels such as insurance agents - the model of online brokers, insurance.

Thirdly, insurance sales staff need to have an enthusiastic, understanding, and professional attitude. To achieve this, these employees need professional training and additional training in communication skills and knowledge of psychology. Insurance officers need the expertise to give accurate instructions, make the documents simple and easy to understand, provide useful information, and consulting affordable insurance packages.

Fourthly, as mentioned in the section, insurance procedures should be streamlined based on standard and legal compliance.

Fifth, the research team recommends that the state and health facilities build a database of citizens' medical records. These medical records may be accompanied by identification or citizenship number. When citizens go for medical examination and treatment, the medical history information can be kept. On the one hand, this profile helps doctors and patients monitor their health status, serve medical examinations, and treat them based on old regimens, family diseases,... On the other hand, for insurance companies, when the customer requests to participate in the non-life insurance policy, the company can ask to access and learn about the customer's medical records (based on privacy 
law), from there can charge more accurately. According to the process, customers wishing to participate in the Pedagogy are required to provide documents about their health status. However, these documents may not even mention the health status of those patients. This patient leads to inaccurate billing that results in revenue loss for the non-life insurance company or leads to dissatisfaction of customers.

\subsection{Attitude towards risk and private health insurance}

The research team proposes the Government to build a strict legal corridor for the participants of the Code of Conduct and insurance companies to implement, both to ensure the health care benefits of the people, to fight against self-interest in insurance but also to help people feel more secure when participating in the Pedagogical Code. At the same time, the state can apply a combined public-private health insurance model, encouraging businesses to buy medical insurance for their employees with tax reduction policies,... In addition, the research team also recommends using software to monitor and remind customers to participate in periodic medical examinations. Regular health care and check-ups can help customers feel more secure when their health is properly cared for and managed.

\subsection{Subject Norms}

As mentioned in previous sections, Subject Norms are defined as the perception of an individual and its influencers that behavior should or should not be performed. That is, a person will want to buy private health insurance if they and the people around them like family, friends, and colleagues feel they should. To achieve this, companies need to consider marketing, communications, and sales strategies:

First, it is necessary to clearly define the market segment, define the target market, and design insurance packages to suit that market segment's needs. Typically there are individual customer segments, small group (home) segments, corporate (companies buying for employees as a type of welfare) segment, senior customer segments, and disabled person. Creating suitable and preeminent insurance packages is the core of being able to sell the insurance package, sign the contract, or not. Besides market segmentation and product design, pricing is also critical.

Second, to ensure that consumers know about the product, understand the need of this product, have easy access to information related to the product, non-life insurance companies can use communication strategies via the Internet, social networking sites, buying search results on Google so that every time a consumer is interested in the product, they can access this information first, as quickly and efficiently as possible. Besides, according to Subject Norms' definition, one can be influenced by others about whether or not they should buy a product so that companies can invest in influencers (in their community) to talk about health insurance products. Alternatively, it is possible to set up a platform for the insured after signing the contract to rate (with stars) and comment so that the manager can both understand the client's problem. However, the point of improvement is that people interested in the product can feel trusted and choose the company.

Third, private health insurance is an exceptional service or commodity that customers sometimes do not understand their products' needs. According to the studies mentioned, typically by Schwarcz (2010), customers will sometimes choose to buy when they do not really need it and not choose a product when it might be useful. Therefore, direct selling is also a good measure, creating a space for insurance agents to advise and persuade customers to buy products. To perform well, staff need professional training in a specific and practical way.

\subsection{Perceived Behavioral Control}

It is one of the sensible behaviors to find out information about a product before buying it to decide whether to buy health insurance or not. To increase this factor's influence, the company can increase its communication and marketing activities, as mentioned above. For health insurance considerations and preparation are part of financial awareness and risk management. People who plan to buy health insurance, in fact, often have financial knowledge, recognize the value and benefits of health insurance products and identify this as a necessary expense so convincing They are not difficult to buy. Nevertheless, the mentality is quite hesitant about spending money on health insurance products - the product is not in urgent need, and the optimistic thought that the risk may not happen and that health is not a big problem for the customer still exists. Therefore, they can see that they need to encourage, promote, and advise the right insurance package. The research team proposes developing direct selling and improving expertise and training insurance sales staff with knowledge of customer psychology.

\section{Limitations and further study}

Although the completed research project still has certain limitations: firstly, the survey sample is still too small compared to the number of health insurance participants in the country. In addition, the selection of localities as the significant research Hanoi may affect the research results because Hanoi is the capital, with better economic, cultural, and educational conditions. Secondly, the limitation of not accessing information about private health insurance customers of non-life insurance companies and interviewing officials of these companies also made the 
research paper incomplete. Also, from this limitation, the research team hopes to conduct further research on a larger scale as a basis for policy issuance and outlining the strategies of non-life insurance companies in private health insurance services in the future.

\section{References}

Auerbach, A. J., \& Kotlikoff, L. J. (1991), 'How rational is the purchase of life insurance?' (No. w3063), Cambridge, MA: National Bureau of Economic Research.

Beck, T., \& Webb, I. (2003), 'Economic, Demographic, and Institutional Determinants of Life Insurance Consumption Across Countries', World Bank Economic Review, 17(1), 51-88.

Berry, L. L. (1995), 'Relationship marketing of services-growing interest, emerging perspectives', Journal of the Academy of Marketing Science, 23(4), 236- 245.

Bhat, R. \& Jain, N. (2006), 'Factoring Affecting the Demand for Health Insurance in a Micro Insurance Scheme', Working paper No. 2006-07-02, Indian Institute of Management, Ahmedabad.

Browne, M. J., \& Kim, K. (1993), 'An international analysis of life insurance demand'. Journal of Risk and Insurance, 60(4), 616-634.

Committee of the Communist Party (2017), Resolution No. 20-NQ / TW about strengthening the protection, care and improvement of people's health in the new situation, the Sixth Conference of the 12th Central, dated October 25th, 2017.

Le Canh Bich Tho, Vo Van Tuan and Truong Thi Thanh Tam, 'Factors affecting the decision on purchasing voluntary health insurance for Can Tho residents', Science Journal of Can Tho University, Volume 48, Part D (2017): 20-25

Lee, S. J., Kwon, S. I., \& Chung, S. Y. (2010), 'Determinants of household demand for insurance: The case of Korea.', The Geneva Papers on Risk and Insurance Issues and Practice, S82-S91.

Nguyen Thi Xuan Huong, Mai Thi Thu Thuy, Nguyen Nhu Bang (2018), 'Factors affecting the people's decision to buy voluntary health insurance in Trang Bom District, Dong Nai Province', Journal of Economics and Development, No. 252 (II), 113-122.

Phuong Chi (2019), '37\% of direct household payments for health services', Nhandan, retrieved on June 14th, 2020, from $<$ https://bom.to/Jyihv1>

Pitriyan, P., \& Siregar, A. Y. M. (2013), 'Health inequity in Indonesia: Is it declining? Working Papers in Economics and Development Studies.', Center for Economics and Development Studies, Department of Economics, Padjajaran University.

Rabin, M., \& Thaler, R. H. (2001), 'Anomalies: Risk aversion.', The Journal of Economic Perspectives, 15(1), 219-232.

Schwarcz, D. (2010), 'Insurance demand anomalies and regulation', Journal of Consumer Affairs, 44(3), 557-577.

Thomas Varghese (2013), 'Determinants of consumer purchase decisions of health insurance in Kerala', Faculty of Social Sciences, Cochin University of Science and Technology.

Yamada, T., Chen, C.C., Yamada, T., Noguchi, H. \& Matthew, M., (2009). 'Private Health Insurance and Hospitalization under Japanese National Health Insurance.', The Open Economics Journal, volume 2, 61 71. 